\title{
Vibration Monitoring of a Large Scale Heavy Haul Railway Viaduct
}

\author{
Fulvio Busatta ${ }^{1, a}$ and Pilate Moyo ${ }^{1}$ \\ ${ }^{1}$ University of Cape Town, Department of Civil Engineering, 7701 Rondebosch, Cape Town, South Africa
}

\begin{abstract}
In South Africa, heavy haul railway transport was introduced in the mid-1970s for the Iron Ore and the Coal Export lines. In recent decades, the expansion of existing mines, new markets and the competition of iron ore- and coalexporting countries have led owners and operators to progressively increase the capacity of the export lines. On the one hand, operational efficiencies have been improved; on the other hand, a significant increase of the rail traffic has been experienced. Thus, bridges along the export lines are now crossed by heavier and longer trains with more frequent train passages than in the past. Increasing train loading might lead to significant consequences on structures such as dynamic amplifications and reduction of service life due to fatigue. Hence dynamic assessment and monitoring of the structural condition of bridges under actual train loading are becoming more relevant to support decision making processes. The paper presents the investigations carried out on the Olifants River Viaduct, a critical structure along the Iron Ore Export Line, in order to implement a state-of-the-art vibration monitoring system.
\end{abstract}

\section{Introduction}

According to the International Heavy Haul Association (IHHA), a heavy haul railroad is conventionally defined as one that meets at least two of the following requirements [1]:

- regularly operates or is contemplating the operation of unit or combined trains of at least 5000 metric tons;

- hauls or is contemplating the hauling of revenue freight of at least 20 million gross tonnes per year over a given line haul segment comprising at least 150 $\mathrm{km}$ in length;

- regularly operates or is contemplating the operation of equipment with axle loadings of 25 tonnes or more.

Heavy haul $(\mathrm{HH})$ railroads have been especially built in USA, Australia, South Africa (SA) and in some European Nordic countries such as Norway and Sweden. In $\mathrm{SA}, \mathrm{HH}$ railway transport was introduced in the mid1970s to export iron ore and coal [2-3]. The Iron Ore Export Line, $861 \mathrm{~km}$ long, connects the mining areas in Sishen, Northern Cape Province, to the Saldanha Bay Harbor in the Western Cape Province; the Coal Export Line, $748 \mathrm{~km}$ long, links the coal mines in Black Hill, nearby Ermelo, Mpumalanga Province, to the Richards Bay Coal Terminal located in Kwazulu-Natal (Fig. 1).

In last decades, the expansion of existing mining areas, new markets, the increasing demand of iron ore and coal and the strong competition of foreign iron ore- and coalexporting countries have led owners and operators to progressively increase the capacity of the export lines in SA. On the one hand, operational efficiencies have been improved; on the other hand, a significant increase of the rail traffic has been performed by [4]:

a) increasing the axle load of wagons; b) increasing the train speed;

c) increasing the number of wagons (i.e. the train length);

d) adding new crossing loops (which accommodate empty trains during the passage of loaded trains) along singletrack lines to increase the number of trains/week.



Figure 1. The Freight Railway Network in South Africa [5].

Increasing the rail traffic on existing railway bridge structures might lead to significant consequences such as:

- larger "live load/dead load" ratios or, from the structural dynamics point of view, larger "train mass/structural mass" ratios;

- dynamic amplification due to resonance phenomena induced by long sequences of wagons;

- reduction of service life due to fatigue when the number of trains significantly increases (coupled with larger axial loads).




Civil structures along the export lines in SA were generally designed with large safety factors to take account for possible higher axle loads, and conservative dynamic amplification factors were adopted at the design stage to evaluate the dynamic response. However, those structures are aging and accelerated deterioration as well as structural defects might arise when they are crossed by heavier and longer freight trains. Therefore, stakeholders have recognized the importance of estimating future enhancements and capacity expansions of $\mathrm{HH}$ lines in SA also based on accurate structural assessments of the existing railway structures e.g. by carrying out vibration testing and monitoring programs.

The paper focuses on one of the most critical civil structures along the Iron Ore Export Line in SA: the Olifants River Viaduct, a prestressed concrete (PSC) 1 $\mathrm{km}$ long structure built in the 1970s and crossed, at present, by the longest $\mathrm{HH}$ train in the world. After this introduction, the subsequent sections of the paper are organized as follows: sections 2 focuses on the viaduct providing a description of the structure, some information on its current health state and the experimental dynamic characterization of the viaduct girder. Section 3 deals with the train loading by providing details on the train configuration and vibration response of the viaduct under train passages. The investigations have been especially targeted at defining and developing a permanent monitoring system which is presented in section 4 . Finally, conclusions are reported in section 5.

\section{The Olifants River Viaduct}

The Olifants River Viaduct (Fig. 2) is located in an agricultural area in the Western Cape Province of SA, between the small towns Lutzville and Vredendal, about $30 \mathrm{~km}$ far from the Atlantic coast. It has been in operation since 1976 when the Iron Ore Export Line was inaugurated. In the following subsections, after providing a description of the viaduct, some selected results from experimental investigations carried out in July and October 2014 are presented and discussed.

\subsection{Description of the structure}

The viaduct consists of a single box PSC girder, $1035 \mathrm{~m}$ long on 23 spans equally spaced, supported by 22 reinforced concrete (RC) piers $45 \mathrm{~m}$ apart (Fig. 3(a)). Two expansion joints are located at the piers \#11-12 so that three structural independent girders result: two major girders, $495 \mathrm{~m}$ long, on spans \#1-11 and \#13-23 respectively, and a short simply supported girder, $45 \mathrm{~m}$ long, on span \#12. The piers \#1-4 and \#20-22 were erected on spread footings (Fig. 3(b)) while piers \#5-19, lying on the bed of the Olifants River, were built on piled foundations having a different number of piles ranging from 8 (pier \#5) to 36 (pier \#19).

The PSC girders are longitudinally post-tensioned members. In addition, they are vertically prestressed by a set of $26 \mathrm{~mm}$ diameter bars introduced inside the webs while transversal prestressing was not applied and the girders do not have transverse beams nor diaphragms.
According to the original technical drawings, concrete grades denoted as $\mathrm{H} 20$ (characteristic cube compressive strength $\left.\mathrm{R}_{\mathrm{ck}}=41 \mathrm{MPa}\right)$ and E20 $\left(\mathrm{R}_{\mathrm{ck}}=34 \mathrm{MPa}\right)$ were used for manufacturing the PSC girders and the RC piers, respectively. Reinforcing steel with $\mathrm{f}_{\mathrm{tk}}=450 \mathrm{MPa}$ and the German prestressing system Holzmann AG with related cables KA40, each consisting of 40 oval ribbed wires, were used for reinforcement and longitudinal posttensioning, respectively.

The viaduct was built by the incremental launching erection method. Hence the cross-section of the girder is uniform along the entire viaduct. As shown in Fig. 3(c), the overall depth of the cross-section is $3.80 \mathrm{~m}$, the width of the bottom flange equals $3.10 \mathrm{~m}$ whereas the top flange (viaduct deck) is $5.50 \mathrm{~m}$ wide in order to host a single ballasted track, two lateral pedestrian passages and parapets. The thickness of the bottom flange along the span is $0.25 \mathrm{~m}$ which becomes $0.65 \mathrm{~m}$ at the supports and midspan in order to accommodate the anchorages of the prestressing tendons. Similarly, the thickness of the top flange equals $0.30 \mathrm{~m}$ and becomes $0.70 \mathrm{~m}$ where anchorages are located. Finally, the vertical webs of the girder have thickness equals $0.35 \mathrm{~m}$.

The three PSC girders are supported by $22 \mathrm{RC}$ tapered piers having a H-type cross-section (Fig. 3(d)) where the flanges are oriented along the longitudinal direction of the viaduct. Due to the variable topography of the Olifants River Valley in which the viaduct is located, the piers have consequently a different height ranging from $17.85 \mathrm{~m}$ (pier \#1) to $51.50 \mathrm{~m}$ (pier \#10). The H-type cross-section has uniform overall depth of $4.60 \mathrm{~m}$; the width linearly increases along the pier axis: at the pier top the width equals $2.40 \mathrm{~m}$ while at the bottom it ranges from $3.65 \mathrm{~m}$ (pier \#1) to $6.00 \mathrm{~m}$ (pier \#10). Finally, the thickness of the cross-section flanges and web equals $0.50 \mathrm{~m}$ and $0.40 \mathrm{~m}$, respectively.

Two different types of bearings are positioned between the girders and piers: i) a reinforced neoprene bearing (RNB) at the piers \#1-4, 11-12 (under the simply supported girder) and 18-22; ii) a sliding bearing (SB) at the piers \#5-9, 11-12 (under the major girders) and 13-17. The RNB approximately behaves as a hinge while the SB behaves as a slider allowing for longitudinal displacements also due to the thermal effects occurring in the long girders. Finally, transversal bearings are located between the girder webs and the pier caps (Fig. 3(d)).

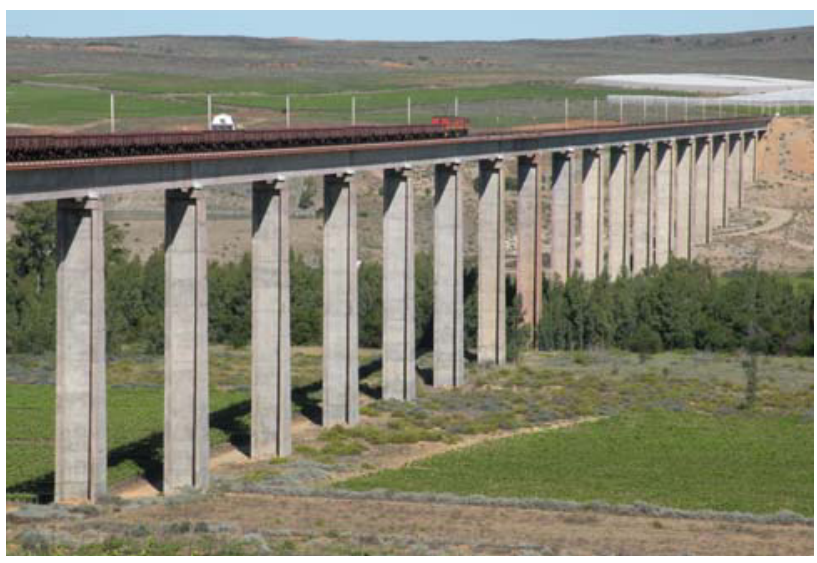

Figure 2. View of the Olifants River Viaduct. 
EVACES'15
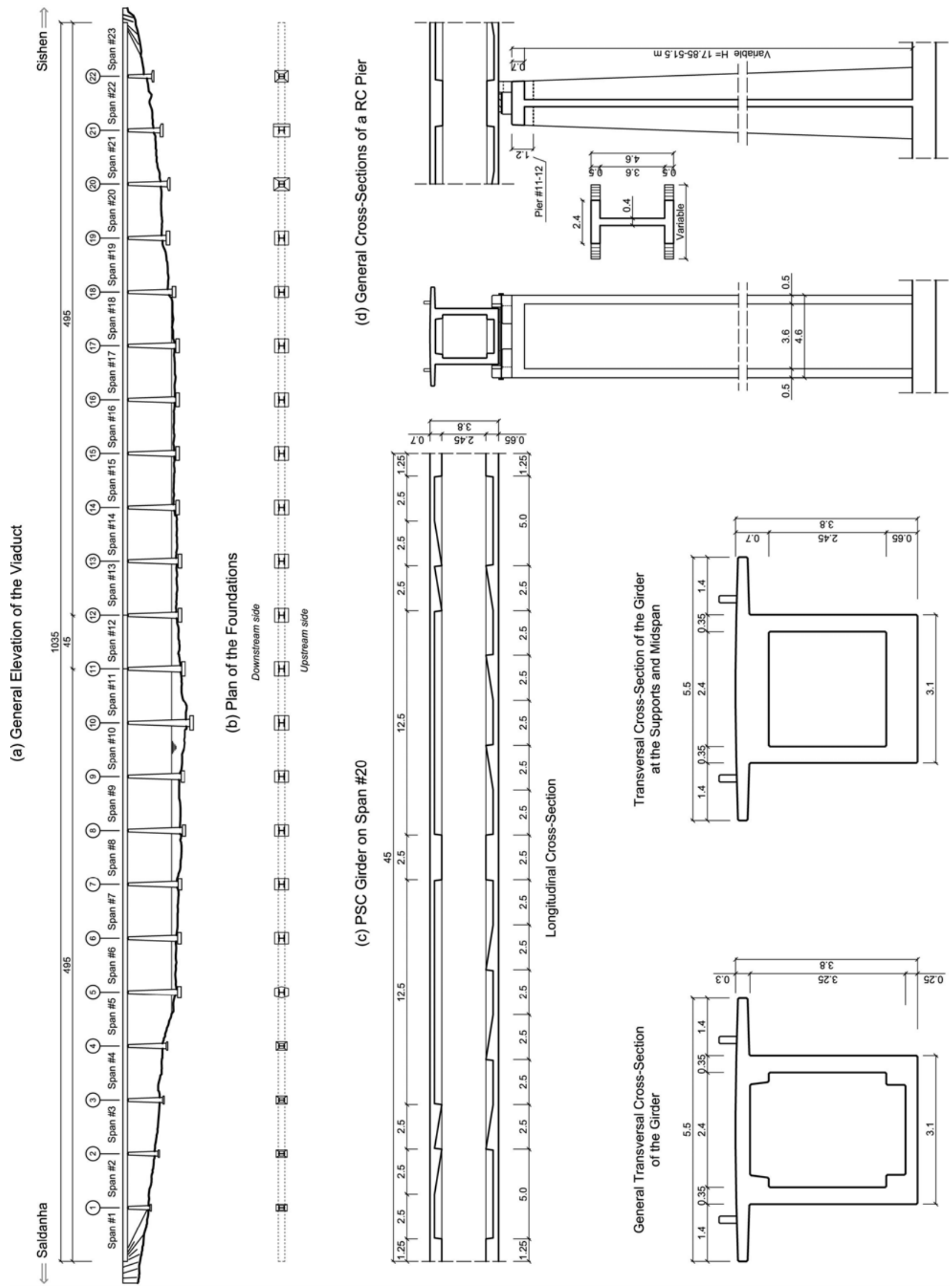

Figure 3. The Olifants River Viaduct: (a) general elevation; (b) plan of the foundations; (c) cross-sections of the PSC girder on span \#20 and (d) cross-sections of a typical RC pier (dimensions in m). 


\subsection{Structural health state}

A preliminary and qualitative evaluation of the health state of the viaduct was performed in July and October 2014 by carrying out visual inspections inside the box girder on the Sishen side (spans \#13-23, see Fig. 3).

A good state of conservation of the concrete material was generally observed, denoting appropriate structural detailing in design and care in the construction process. In addition, being the viaduct located in an agricultural area far from the Atlantic Ocean, the environment is not significantly harsh.

However, some significant cracking phenomena were detected inside the girder, generally in the thicker parts of the flanges. Fig. 4 summarizes the cracks in span \#20: at the supports, significant longitudinal cracks were generally observed in the middle of top and bottom flanges with propagation on the entire thicker part of the flange (Fig. 4(a)); at mid-span, significant cracks generally occur at the top corners, again with propagation on the entire thicker part of the flange (Fig. 4(b)). Similar cracking phenomena were observed also in other spans of the girder so that the cracks in span \#20 appear to be recurrent crack patters.

The interpretation of the nature of cracking is generally challenging since many factors can contribute to the phenomenon. However, the lack of transversal prestressing as well as of transverse beams/diaphragms in the viaduct seems to play a significant role. In addition, a lack of transversal reinforcing steel bars in the thicker parts of the flanges at the supports was observed in the original technical drawings. Thus, when train loading and related reactions at the bearings occur, high tensile stresses arise in the top and bottom flanges, respectively, which might not properly managed by the existing steel reinforcement. In the mid-span section, stresses due to train loading and transversal effects related to the longitudinal bending behavior of the girder lead to recurrent cracking patters as well.

(a)
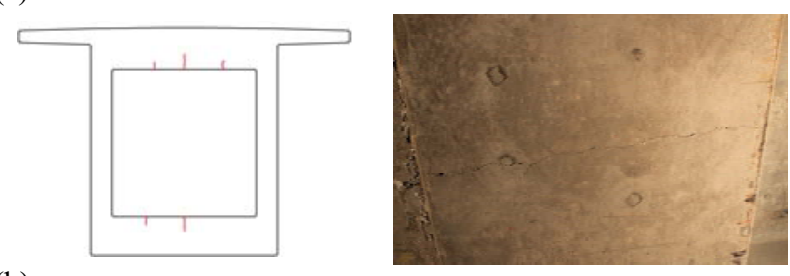

(b)
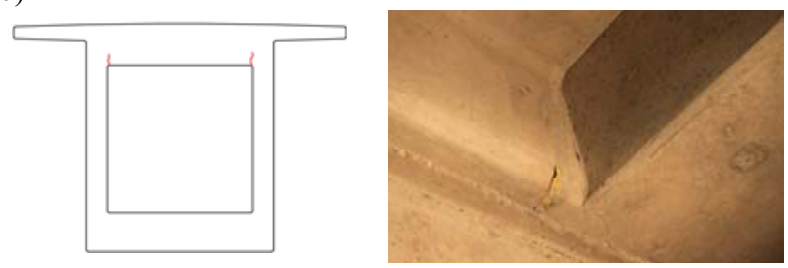

Figure 4. Crack phenomena detected in span\#20 at (a) the supports and (b) midspan sections.

The crack widths and propagation lengths appeared to be more significant than those observed in an inspection and testing campaign performed in 2007 [6] before the introduction of a new Radio Distributed Power (RDP) freight train [7] which is described in section 3. Thus, it seems appropriate performing:

a) Nondestructive Testing to quantitatively characterize the most significant cracks, and get information on the steel reinforcement bars at the supports;

b) crack monitoring in some selected cross-sections at the supports to investigate the evolution of the crack width over time;

c) strain monitoring at the supports and midspan crosssections to investigate the evolution of the tensile stresses in the concrete at some selected points close to the most significant existing cracks.

\subsection{Dynamic testing and modal analysis}

Dynamic tests in operating conditions were performed in July and October 2014 on the girder Sishen side (spans \#13-23, see Fig. 3) in order to investigate the modal properties of the girder and the vibration response of the girder during train passages which is discussed in section 3 . It is worth mentioning that, for our knowledge, those tests represented the first dynamic investigations carried out to characterize the dynamic behavior of the viaduct and the vibration response under the RDP train.

The first dynamic test was performed during a 1-day site visit on July $25^{\text {th }} 2014$. The test aimed at performing a preliminary investigation on the vertical $(\mathrm{V})$, transversal (T) and longitudinal (L) dynamic behavior of the girder by collecting acceleration time histories of time length $\tau=900 \mathrm{~s}\left(15^{\prime}\right)$, with sampling frequency $f_{\mathrm{s}}=1024 \mathrm{~Hz}$ at 5 instrumented positions on half span \#22. A description of that test and first results on the dynamic behavior of the girder in the $\mathrm{V}$ and $\mathrm{T}$ directions are reported in [8]. Some conclusions of that test are as follows:

i) the $1^{\text {st }}$ vertical bending (VB) mode of vibration of the girder was clearly identified at $f_{\mathrm{PP}}=4.11 \mathrm{~Hz}$ where the subscript PP stands for Peak-Picking [9], the method used to investigate the frequency peaks;

ii) close transversal bending (TB) modes of vibration characterize the girder behavior in the low frequency range $0-5 \mathrm{~Hz}$ and the first mode was clearly identified at $f_{\mathrm{PP}}=1.288 \mathrm{~Hz}$. However, lower frequency TB modes seem identifiable around $1 \mathrm{~Hz}$ by collecting longer ambient vibration signals at a greater number of instrumented positions properly located.

The second dynamic test was performed during a 4-day site visit on October $7^{\text {th }}-10^{\text {th }} 2014$. The test aimed at better understanding the $\mathrm{V}, \mathrm{T}$ and $\mathrm{L}$ dynamic behavior of the girder. Hence a more comprehensive test was performed by collecting acceleration time histories of time length $\tau=1300 \mathrm{~s}$ (21.6'), with sampling frequency $f_{\mathrm{s}}=1024 \mathrm{~Hz}$ at 42 instrumented positions distributed on half span \#19, the entire span \#20 and half span \#21. Fig. 5 shows a schematic with a) the distribution of the instrumented position along 21 cross-sections of the girder generally $5 \mathrm{~m}$ apart plus the cross-sections \#1, 11 and 21 at midspan; b) the directions of the accelerometers and c) the location of reference sensors. 


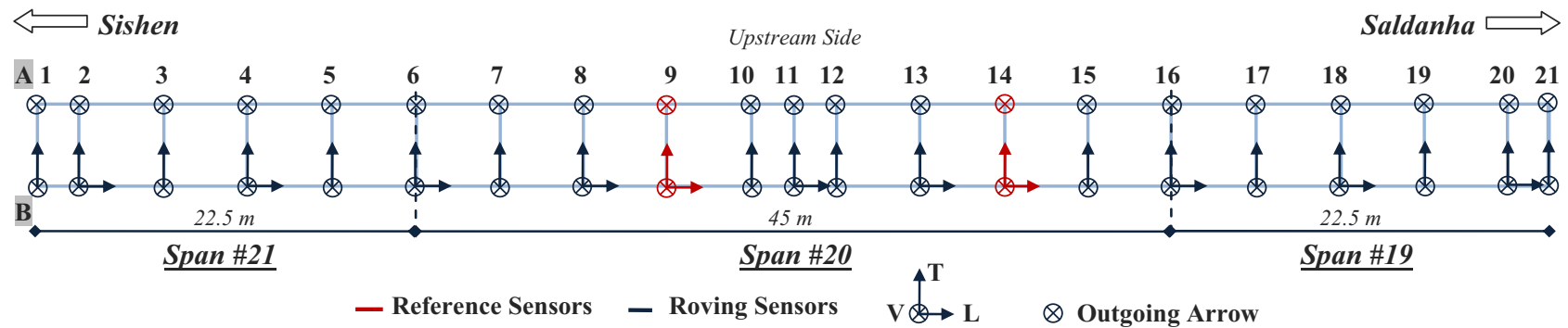

Figure 5. Dynamic test in Oct 2014: instrumented positions and directions of the sensors.

The test was performed by 8 reference sensors at crosssections \#9 and \#14 and 7 roving sensors at first located at cross-sections \#1-2 (Setup \#1) then at cross-sections \#3-4 (Setup \#2) and so on for a total number of 10 setups.

In terms of equipment, 15 force-balance Honeywell QFlex QA-700 current output accelerometers with related cabling, a power supplier and a PC-based data acquisition (DAQ) system hosting 2 National Instruments (NI) PCI4472B 8-channels, 24-bit resolution boards were used. DC coupling was used in recording the electric signals. The accelerometers QA-700 accelerometers were attached to the structure by using magnets on steel plates glued on the concrete surface (Fig. 6).

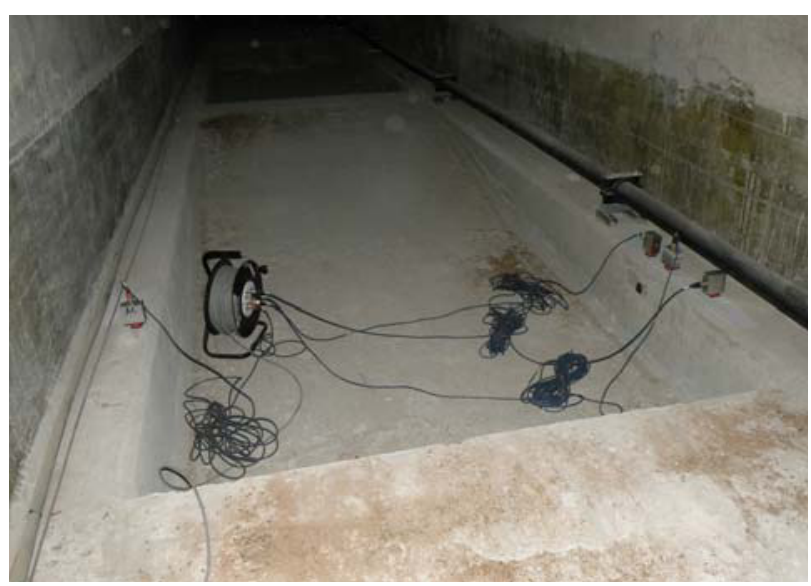

Figure 6. Dynamic test in Oct 2014: four QA-700 accelerometers deployed on the concrete girder.

The Operational Modal Analysis (OMA) was performed by both the Frequency Domain Decomposition (FDD) [10] and the Stochastic Subspace Identification [11] based on Principal Component (SSI-PC) techniques as implemented in the commercial software ARTeMIS [12]. A frequency resolution $\mathrm{d} f=0.0125 \mathrm{~Hz}$ was used in estimating the spectral matrix of both $\mathrm{V}$ and $\mathrm{T}$ signals. Fig. 7(a) and 7(b) show the singular value (SV) lines resulting from the SVD of the spectral matrix $\mathbf{G}(f)$, the $\mathrm{VB} /$ Torsion (TO) modes and 12 selected mode shapes of the TB modes, respectively. The identified modes of vibration are listed in Table 1 excluding the longitudinal modes do not discussed in this paper. Key remarks on the $2^{\text {nd }}$ vibration test are as follows:

i) the $1^{\text {st }} \mathrm{VB}$ mode of vibration of the girder is confirmed being at $4.1 \mathrm{~Hz}$;

ii) four additional VB modes and two TO modes were identified by the FDD technique in the frequency range $0-20 \mathrm{~Hz}$; iii) the transversal behavior of the girder is characterized by several close TB modes in the frequency range 0-5 Hz. A $1^{\text {st }}$ TB mode was identified at $f_{\mathrm{FDD}}=0.975 \mathrm{~Hz}$. However, considering the mode shapes in Fig. 7(b) and the identified modes by the SSI-PC, the TB modes around $1 \mathrm{~Hz}$ (i.e. modes $\mathrm{TB}_{1}-\mathrm{TB}_{4}$ ) (see Fig. 7(b)) need a further more comprehensive investigation in order to understand if any of them is in fact related to a local vibration mode of a pier;

iv) even though separately listed, modes $\mathrm{TB}_{13}-\mathrm{TB}_{14}$, identified by the FDD technique, show highly correlated mode shapes $(\mathrm{MAC}=0.99)$ denoting the occurrence of a single mode in those SV line peaks. That mode is identified at $3.762 \mathrm{~Hz}$ by the SSI-PC technique;

v) a good agreement was generally observed in terms of natural frequencies for the identified $\mathrm{VB} / \mathrm{TO} / \mathrm{TB}$ modes by the FDD and SSI-PC techniques. Estimated damping ratios provided by the SSI-PC technique are generally as expected for a PSC large-scale multispan structure;

Table 1. Dynamic test in Oct 2014: identified vibration modes.

\begin{tabular}{|c|c|c|c|}
\hline \multicolumn{4}{|c|}{ a) Vertical Dynamic Behavior } \\
\hline Mode \# & $f_{\mathrm{FDD}}(\mathrm{Hz})$ & $f_{\text {SSI-PC }}(\mathbf{H z})$ & $\zeta_{\text {SSI-PC }}(\%)$ \\
\hline $\mathrm{VB}_{1}$ & 4.075 & 4.073 & 1.318 \\
\hline $\mathrm{VB}_{2}$ & 4.7 & - & - \\
\hline $\mathrm{VB}_{3}$ & 5.025 & 5.01 & 2.476 \\
\hline $\mathrm{VB}_{4}$ & 6.45 & 6.405 & 2.569 \\
\hline $\mathrm{TO}_{1}$ & 10.35 & 10.357 & 1.805 \\
\hline $\mathrm{VB}_{5}$ & 14.45 & 14.537 & 1.382 \\
\hline $\mathrm{TO}_{2}$ & 17.75 & 17.744 & 0.827 \\
\hline \multicolumn{4}{|c|}{ b) Transversal Dynamic Behavior } \\
\hline Mode \# & $f_{\mathrm{FDD}}(\mathrm{Hz})$ & $f_{\text {SSI-PC }}(\mathbf{H z})$ & $\zeta_{\text {SSI-PC }}(\%)$ \\
\hline $\mathrm{TB}_{1}$ & 0.975 & - & - \\
\hline $\mathrm{TB}_{2}$ & 1.05 & - & - \\
\hline $\mathrm{TB}_{3}$ & 1.125 & - & - \\
\hline $\mathrm{TB}_{4}$ & 1.20 & - & - \\
\hline $\mathrm{TB}_{5}$ & 1.275 & - & - \\
\hline $\mathrm{TB}_{6}$ & 1.425 & 1.416 & 1.574 \\
\hline $\mathrm{TB}_{7}$ & 1.50 & - & - \\
\hline $\mathrm{TB}_{8}$ & 1.675 & 1.672 & 1.745 \\
\hline $\mathrm{TB}_{9}$ & 1.95 & 1.957 & 1.157 \\
\hline $\mathrm{TB}_{10}$ & 2.325 & 2.329 & 1.229 \\
\hline $\mathrm{TB}_{11}$ & 2.775 & 2.749 & 1.244 \\
\hline $\mathrm{TB}_{12}$ & 3.175 & 3.176 & 0.772 \\
\hline $\mathrm{TB}_{13}$ & 3.725 & 3762 & 1583 \\
\hline $\mathrm{TB}_{14}$ & 3.80 & 5.102 & 1.583 \\
\hline $\mathrm{TB}_{15}$ & 4.225 & - & - \\
\hline
\end{tabular}



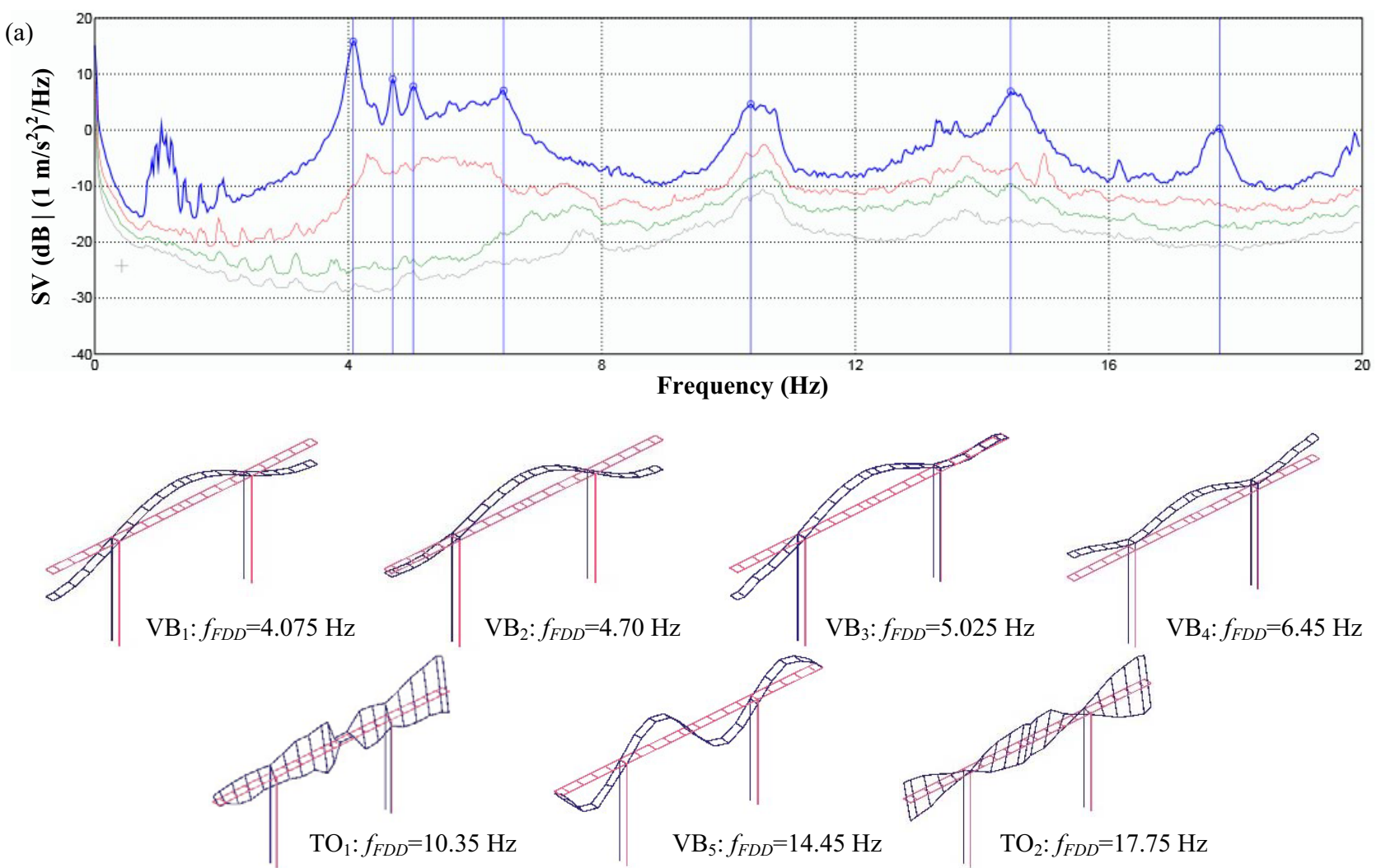

(b)
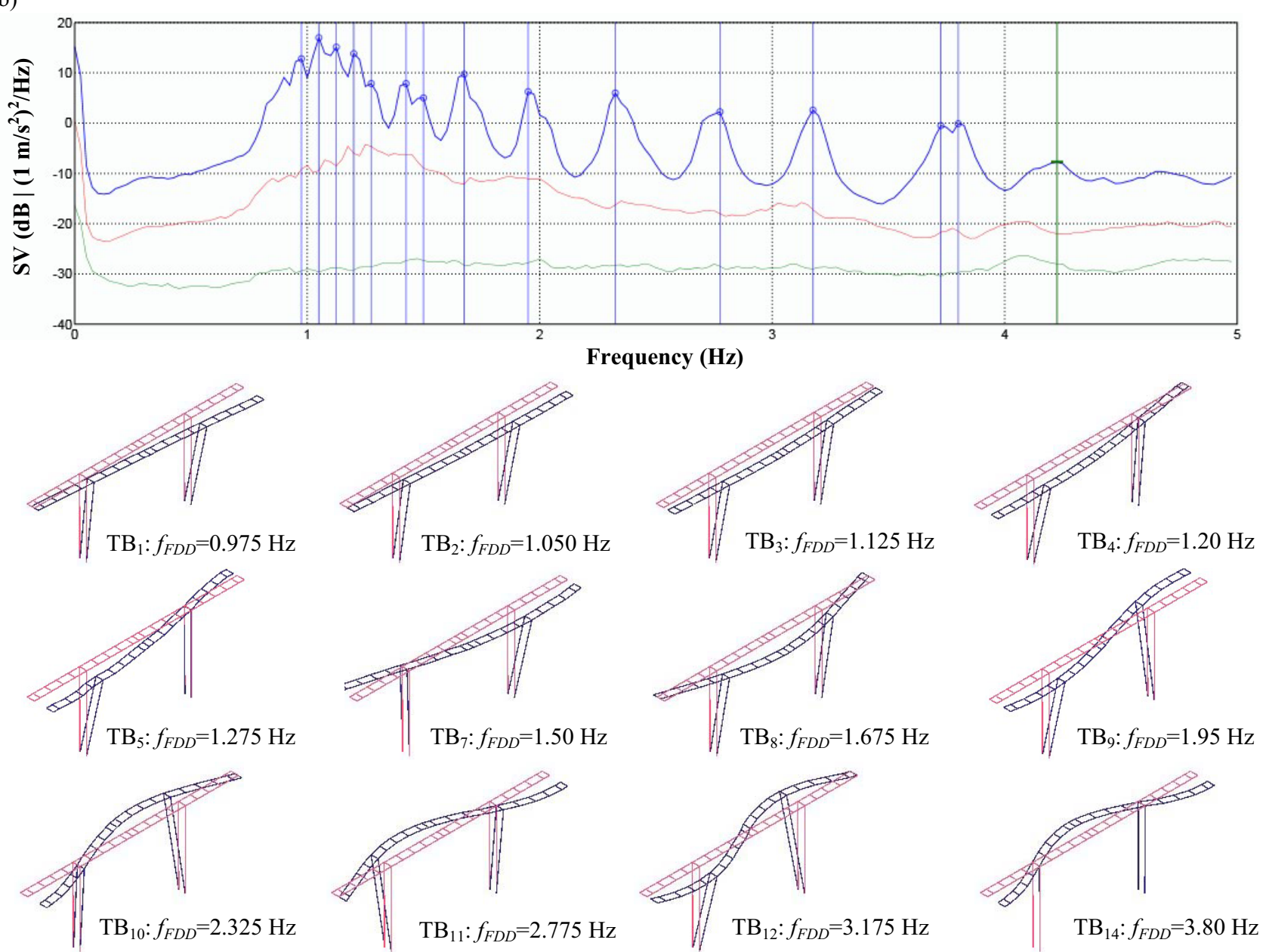

Figure 7. Dynamic test in Oct 2014: (a) SV lines of the vertical behavior and VB/TO modes identified in the frequency range $0-20 \mathrm{~Hz}$; (b) SV lines of the transversal behavior and 12 selected TB modes identified in the frequency range $0-5 \mathrm{~Hz}$. 


\section{The heavy haul train loading}

The Iron Ore Export Line is a single-track railway line on a narrow gauge $(1067 \mathrm{~mm})$. It has been in operation since 1976 and currently it is the $2^{\text {nd }}$ longest heavy haul railway line in the world [4]. The line owner and operator is Transnet, a State Owned Company that manages the line by the operational division Transnet Freight Rail (TFR).

Trains loaded with iron and manganese ores leave the station in Sishen to reach, after a route of $861 \mathrm{~km}$, the commercial port in Saldanha. Conversely, empty trains with the same configuration of loaded trains departure from the commercial port to return to the mining areas. Empty and loaded trains cross the line at a maximum speed of 70 and 60 $\mathrm{km} / \mathrm{h}$, respectively; on the viaduct, their speed reduces to 40 50 and $30-40 \mathrm{~km} / \mathrm{h}$, respectively. A recent upgrade of the line resulted in new crossing/passing loops and in the lengthening of the existing ones to $4.5 \mathrm{~km}$. Hence, the number of trains crossing the line has significantly increased to 38 trains/week at present. The current number of trains has doubled from the 1970s and a greater number of trains (42/week) has been already planned by TFR.

In the following subsections, details on the train configuration and related axle loads are provided in 3.1; subsection 3.2 focuses on the structural response of the viaduct girder when crossed by the RDP train.

\subsection{Train configuration and rail traffic}

Since 2007, a new freight train based on the RDP technology has been introduced on the Iron Ore Export Line [7]. The RDP technology allows to safely manage locomotive consists distributed at intermediate points of the train so that the number of wagons can be significantly increased as a result of the greater and distributed power. As a consequence, a train configuration with 4 Locomotive Consists (LC) and 342 Wagons (W), distributed in three rakes of 114 cars, has been adopted as follows:

LC"A"+114W+LC"B"+114W+LC"C"+114W+LC"D"

The configurations of the locomotive consists A-D is described in detail in Table 2 where E stands for Electric and $\mathrm{D}$ for Diesel locomotives.

Table 2. Layouts of the locomotive consists.

\begin{tabular}{|c|c|c|c|c|}
\hline Layout & LC"A" & LC"B" & LC"C" & LC"D" \\
\hline \hline$(1)$ & $2 \times 15 \mathrm{E}$ & $1 \times 15 \mathrm{E}$ & $1 \times 15 \mathrm{E}$ & $\begin{array}{c}1 \times 15 \mathrm{E} \text { or } \\
1 \times 9 \mathrm{E}\end{array}$ \\
\hline$(2)$ & $\begin{array}{c}1 \times 15 \mathrm{E} \\
+1 \times 43 \mathrm{D}\end{array}$ & $\begin{array}{c}1 \times 15 \mathrm{E} \\
+1 \times 43 \mathrm{D}\end{array}$ & $1 \times 15 \mathrm{E}$ & $\begin{array}{c}1 \times 15 \mathrm{E} \text { or } \\
1 \times 9 \mathrm{E}\end{array}$ \\
\hline
\end{tabular}

The three different types of locomotives $15 \mathrm{E}, 9 \mathrm{E}$ and 43D are illustrated in Fig. 8(a-c), respectively. Similarly, Fig. 8(d) shows an elevation of the wagon type CR13 used to transport the iron ore. The wagon CR13 has a gross weight of $200 \mathrm{kN}$ (20 tonnes). When fully loaded, the wagon static weight equals $1200 \mathrm{kN}$ (120 tonnes), resulting in 300 $\mathrm{kN} /$ axle $(30 \mathrm{t} / \mathrm{axle})$. The total length of the three rakes of wagons is approximately $3.85 \mathrm{~km}$ [7] which becomes 4.1 $\mathrm{km}$ including the locomotive consists [4]. At present the RDP train of TFR is the longest freight train in the world and three times longer than the Olifants River Viaduct. However, TFR is currently working on the upgrade of the RDP Train introduced in 2007 to both increase the number of wagons and the axle load.

(a)

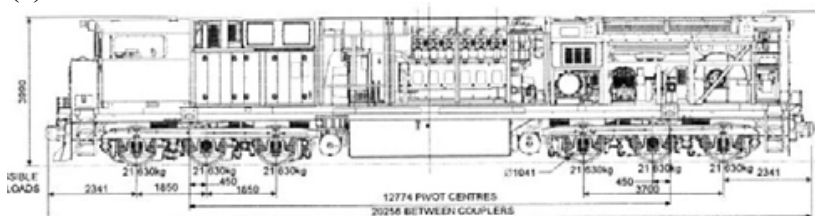

(b)

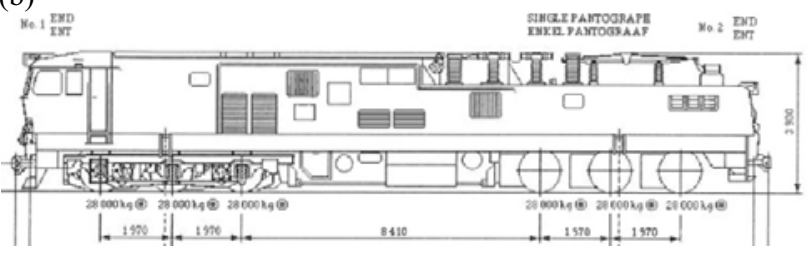

(c)

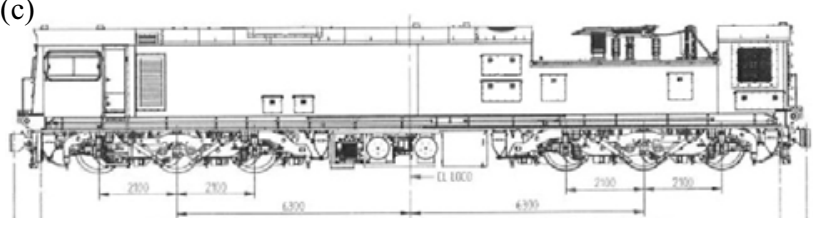

(d)

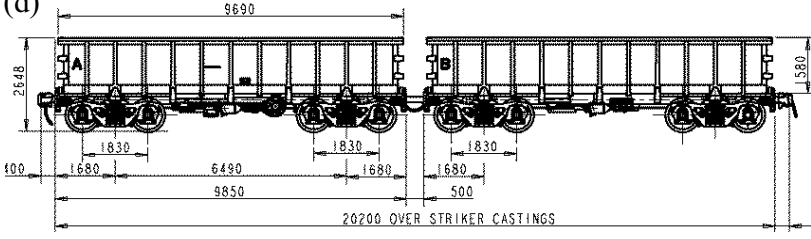

Figure 8. Schematic of locomotives (a) 43D - $216 \mathrm{kN} / \mathrm{axle}$, (b) $9 \mathrm{E}-280$ $\mathrm{kN} /$ axle and (c) $15 \mathrm{E}-300 \mathrm{kN} / \mathrm{axle}$ and wagon (d) CR13 - $300 \mathrm{kN} / \mathrm{axle}$.

\subsection{Structural response under train passages}

The structural response of the viaduct girder under train passages was recorded in terms of both acceleration and strain time histories in October 2014.

In terms of strains, three resistance-based HBM SLB700A strain transducers were deployed inside the girder at the cross-section on pier \#21 (see Fig. 3). Fig. 9(a) shows the strain time history recorded during the passage of a loaded train by a strain transducer vertically attached on the girder web. The strain time histories were collected with $f_{\mathrm{s}}=128 \mathrm{~Hz}$. That sampling rate was high enough to properly record the strain variation due to the RDP train; however a further test with a higher sampling rate will be performed to better describe the sequence of axle loads. Focusing on the strain time history generated by the sequence of the CR13 wagons, a pseudo-periodic strain signal was observed (Fig. 9(b)). Thus, the vibration strain time histories generally allows for: a) estimating the train speed being both the wagon size and axle distance known and assuming uniform motion of the train. In the example of Figure 9 the train speed was estimated being around $32 \mathrm{~km} / \mathrm{h}$; b) estimating the period of the pseudo-periodic signal induced by the long sequence of wagons and so the period of the train loading. As Fig. 9(b) suggests, the period of the wagon loading is generally close to $1 \mathrm{~s}$; c) estimating the variation of stresses in the concrete material if an estimation of the elastic modulus of the concrete is available. 


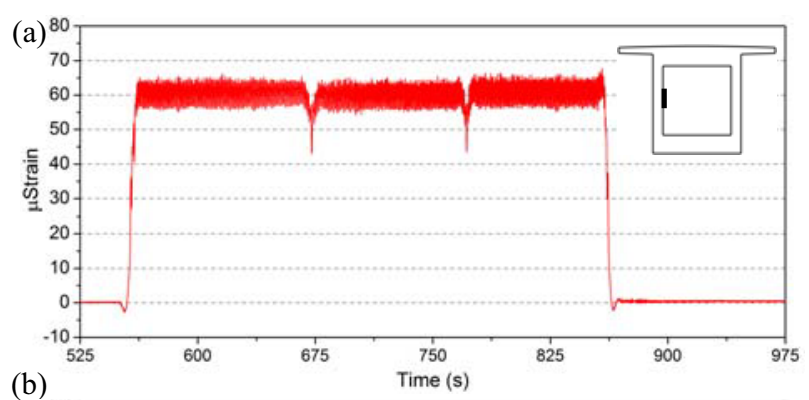

(b)



Figure 9. Dynamic test in Oct 2014: (a) example of strain signal due to a loaded train; (b) pseudo-periodic wagon induced signal.

The same loaded train passage was recorded in terms of acceleration with $f_{\mathrm{s}}=1024 \mathrm{~Hz}$ at the four reference positions (see Fig. 5). Train signals $350 \mathrm{~s}$ long $\left(\approx 6^{\prime}\right)$ were extracted and detrended. Fig. 10 shows the acceleration response as collected at the position \#B14 along the $\mathrm{V}, \mathrm{T}$ and $\mathrm{L}$ directions. Large signal amplitudes were observed in the $\mathrm{T}$ direction reasonably due to irregularities on train wheels and rails and generally associated to high frequency values. Table 3 summarizes RMS of the acceleration $a_{\text {RMS }}$ and the peak acceleration $a_{\mathrm{P}}$ values of the train signals. The values are listed for both the measured and filtered signals. The latter were filtered by applying a signal filtering LabVIEW tool $[13,14]$ set with a low-pass Butterworth filter, frequency cutoff of $25.6 \mathrm{~Hz}$ for the $\mathrm{V}$ signals and $12.8 \mathrm{~Hz}$ for the $\mathrm{T}$ and $\mathrm{L}$ signals as in the estimation of $\mathbf{G}(f)$. As expected, the filtered signals denote as the $\mathrm{V}$ response is the greatest than the ones along the $\mathrm{T}$ and $\mathrm{L}$ directions.

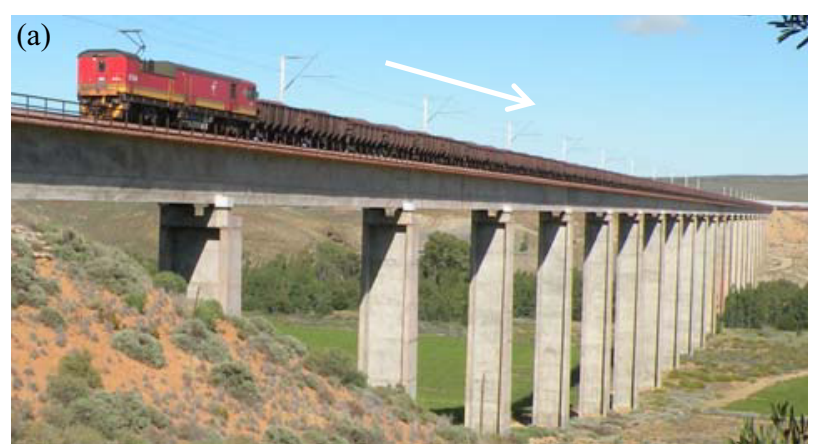

(b)

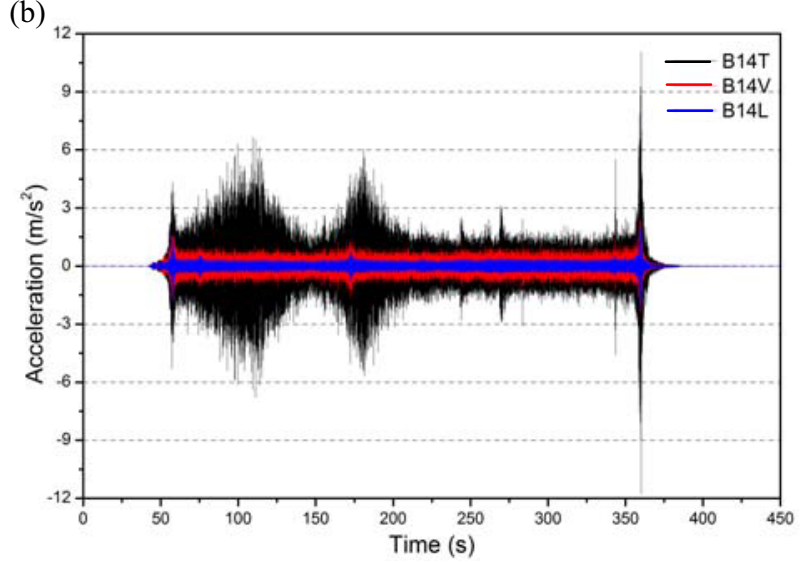

Figure 10. Dynamic test in Oct 2014: (a) a loaded train on the viaduct; (b) acceleration signals collected at position \#B14.
Table 3. Statistics on the RDP loaded train acceleration signals.

\begin{tabular}{|c|c|c|c|c|}
\hline Position & \multicolumn{2}{|c|}{ Measured Signals } & \multicolumn{2}{c|}{ Filtered Signals } \\
\hline \hline$\#$ & $\boldsymbol{a}_{\boldsymbol{R M S}}\left(\boldsymbol{m} / \mathbf{s}^{\mathbf{2}}\right)$ & $\boldsymbol{a}_{\boldsymbol{P}}\left(\boldsymbol{m} / \mathbf{s}^{\mathbf{2}}\right)$ & $\boldsymbol{a}_{\boldsymbol{R M S}}\left(\boldsymbol{m} / \mathbf{s}^{2}\right)$ & $\boldsymbol{a}_{\boldsymbol{P}}\left(\boldsymbol{m} / \mathbf{s}^{\mathbf{2}}\right)$ \\
\hline A9V & 0.209 & 2.14 & 0.058 & 0.30 \\
B9V & 0.201 & 2.09 & 0.057 & 0.29 \\
A14V & 0.247 & 2.12 & 0.049 & 0.26 \\
B14V & 0.269 & 2.40 & 0.049 & 0.26 \\
\hline B9T & 0.599 & 9.51 & 0.017 & 0.06 \\
B14T & 0.943 & 11.08 & 0.016 & 0.08 \\
\hline B9L & 0.359 & 5.39 & 0.006 & 0.03 \\
B14L & 0.116 & 2.05 & 0.006 & 0.03 \\
\hline
\end{tabular}

The train acceleration signals $350 \mathrm{~s}$ long were also analyzed to investigate frequency content and excited vibration modes during a train passage. For example, Fig. 11 shows the $\operatorname{ANPSD}(f)$ in the $\mathrm{V}$ direction in the frequency range 3-12 Hz. The plot compares the ANPSD $(f)$ of train signals to the one computed from ambient vibration signals (depicted at a larger scale) both estimated with $\mathrm{d} f=0.0125 \mathrm{~Hz}$. The "Ambient" ANPSD $(f)$ was estimated from signals $3600 \mathrm{~s}$ long obtained by linking (after detrending) the ambient vibration signals collected in the reference positions A9/B9 and A14/B14 during the execution of the setups.

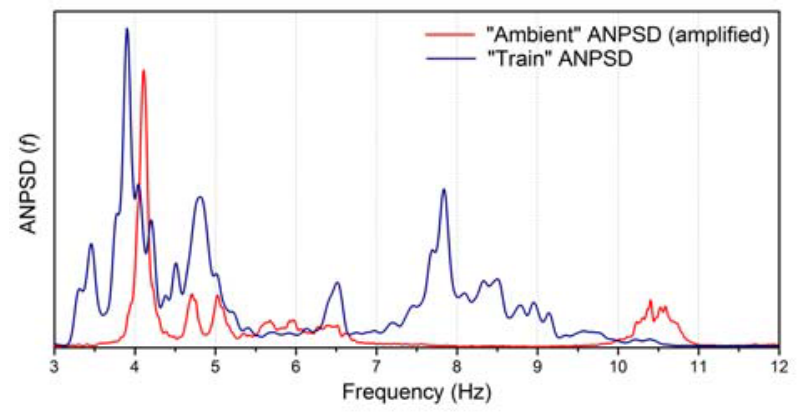

Figure 11. Dynamic test in Oct 2014: frequency content of the $\operatorname{ANPSD}(f)$ from vertical ambient vibration and train signals.

Table 4 compares the natural frequencies of the structure identified by the PP technique from ambient vibration and train signals. As Figure 10 and Table 4 show:

- VB modes are generally excited during train passages. Quasi-antisymmetrical modes at girder level (such as the mode $\mathrm{VB}_{1}$ ) generally shift their frequency peak at a lower value due to the effect of the train mass;

- TO modes are not clearly excited during a train passages as expected in a structure hosting a single-track rail line.

Table 4. Comparison of vertical identified natural frequencies from ambient vibration and train signals.

\begin{tabular}{|c|c|c|}
\hline Mode & Ambient Signals & Train Signals \\
\hline$\#$ & $\boldsymbol{f}_{\boldsymbol{P P}}(\boldsymbol{H z})$ & $\boldsymbol{f}_{\boldsymbol{P P}}(\boldsymbol{H z})$ \\
\hline $\mathbf{V B}_{\mathbf{1}}$ & 4.1 & 3.885 \\
\hline $\mathbf{V B}_{\mathbf{2}}$ & 4.7 & 4.489 \\
\hline $\mathbf{V B}_{\mathbf{3}}$ & 5.0125 & 4.8 \\
\hline $\mathbf{V B}_{\mathbf{4}}$ & 6.45 & 6.5 \\
\hline $\mathbf{T O}_{\mathbf{1}}$ & 10.388 & - \\
\hline $\mathbf{V B}_{\mathbf{5}}$ & 14.575 & 14.8 \\
\hline $\mathbf{T O}_{\mathbf{2}}$ & 17.563 & - \\
\hline
\end{tabular}




\section{The monitoring system}

A monitoring system, based on a limited number of sensors, has been designed and developed by the Concrete Materials and Structural Integrity Research Unit (CoMSIRU) of the University of Cape Town. Preliminary versions of the system were presented in $[8,16]$.

The monitoring system consists of 36 sensors (8 accelerometers, 16 strain transducers, 4 crack sensors and 8 thermocouples) distributed along a single span of the viaduct as shown in Fig. 12. Data acquisition (DAQ) and synchronization of the 36 sensors are managed by a NI CRIO device and an expansion chassis both equipped with NI C Series DAQ modules. The entire hardware is arranged in two panels each other connected, with the NI C-RIO and chassis hosted in Panel\#1 and \#2, respectively (Fig. 12). The Panel \#1 also hosts a small industrial PC to manage the data transferring by the Internet. Panels and LabVIEW [14] DAQ software running in the C-RIO have been developed in cooperation with KAIROS [15].

At present, the installation of the system has been planned in early September 2015 on span \#20 being observed the occurrence of cracking phenomena at both the supports on piers \#19-20 and vibration modes generally well defined in that span. However, a further comprehensive vibration test will be performed to select the optimal span.
In addition, it is worth mentioning that:

- the architecture of the monitoring system was conceived to be easily scalable so that further expansion chassis could be added in series for the DAQ of further sensors placed on the nearby spans;

- both continuous and event monitoring will be performed. The latter aims at collecting the train signals at higher sampling rates than those used in the continuous monitoring.

The major goals of the monitoring system are as follows:

a) Vibration monitoring i.e. monitoring of the natural frequencies of the girder (Sishen side) and the response induced by the RDP train by both using accelerometers and strain transducers;

b) Strain monitoring i.e. monitoring of the variation of strains (and stresses) in the concrete material at positions close to the major cracks. In addition, monitoring of the curvature will be performed by the longitudinal strain transducers;

c) Crack monitoring i.e. monitoring of the width of the most significant cracking phenomena;

d) Temperature monitoring to investigate the variation of the temperature in the cross-section at the pier \#19 and the possible thermal influence on cracks width, natural frequencies and in general on the structural response.
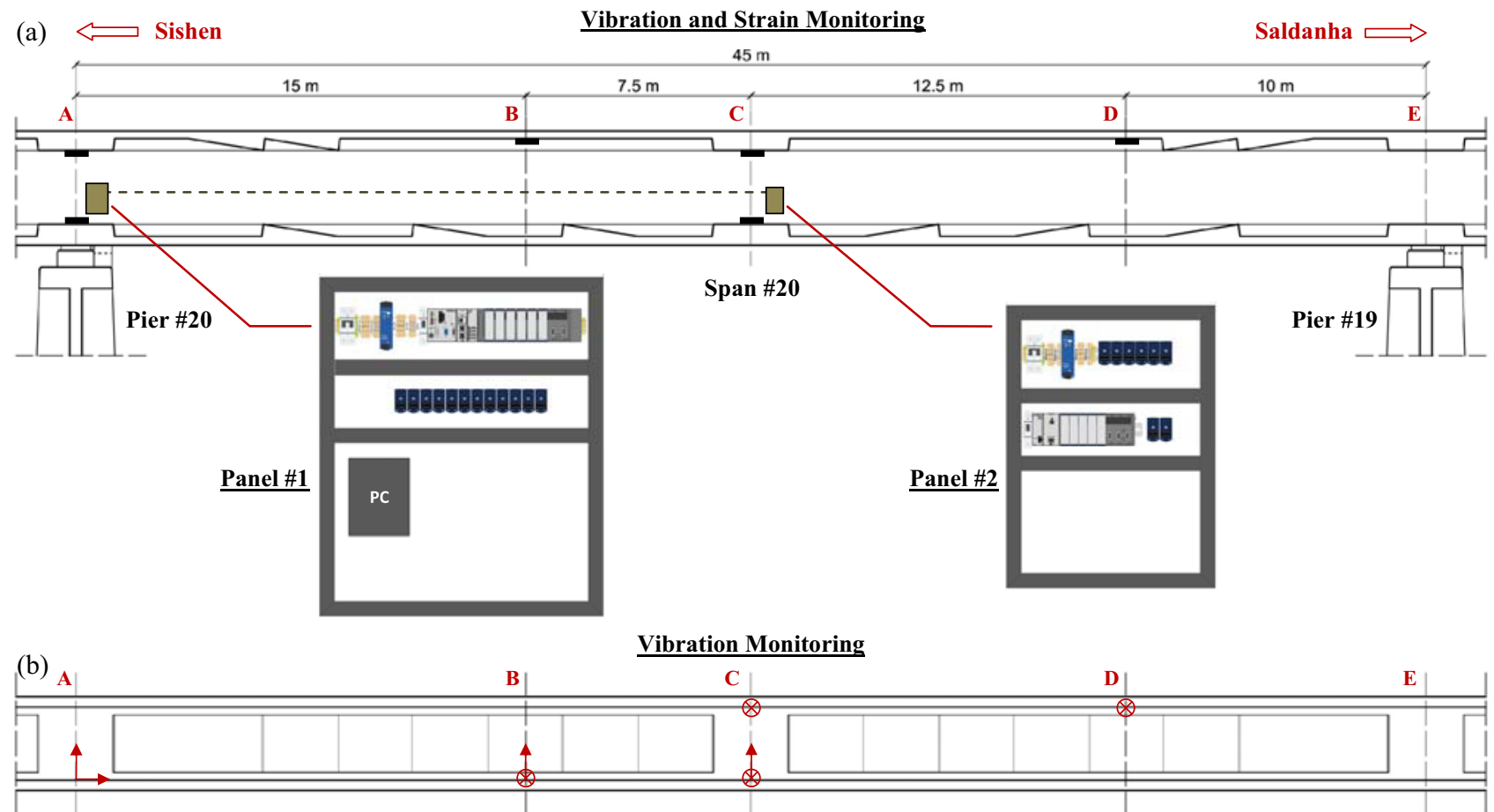

(c) Vibration and Strain Monitoring
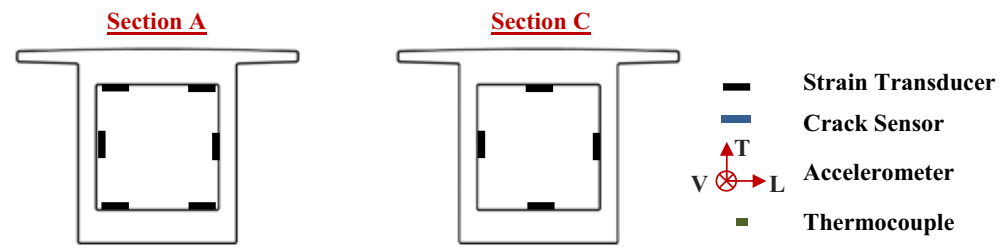

(d)

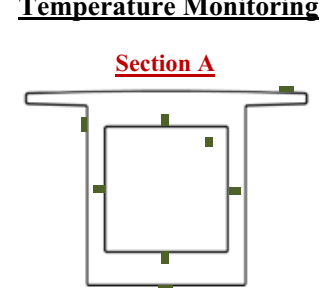

(e) Crack Monitoring

Figure 12. Schematic of the monitoring system and placement of: (a) longitudinal strain transducers and electric panels; (b) accelerometers; (c) transversal strain transducers; (d) thermocouples, and (e) crack sensors. 


\section{Conclusions}

The paper focused on the Olifants River Viaduct located along the Iron Ore Export Line in SA. Due to the large scale of the girders and tall piers, the viaduct is a critical structure wherein condition assessment and maintenance are generally challenging tasks. Since the year of opening, the viaduct has experienced a significant increase of rail traffic and is crossed nowadays by the longest heavy haul freight train in the world. Some investigations were performed to assess the structural condition of the girder, Sishen side, and define a monitoring system.

The main concluding remarks of this paper are as follows: - significant cracking phenomena have occurred inside the girder and some recurrent crack patters were detected. Crack characterization and monitoring seem necessary; - vibration testing and OMA highlighted a complex behavior of the girder, especially in the transversal direction. A further more comprehensive vibration test will be performed to better characterize some VB modes $\left(\mathrm{VB}_{2}-\mathrm{VB}_{3}\right)$ and investigate the TB modes around $1 \mathrm{~Hz}$;

- a monitoring system, to support the condition assessment of the viaduct over time, has been defined and fully developed at present. Vibration-based monitoring by both collecting strain and acceleration signals, strain monitoring, cracking monitoring and temperature monitoring are the main targets of the system;

- the identification of the modal properties of the girder also aims at establishing a sound experimental basis for implementing and checking analytical models of the viaduct as a future research work. Those models would aim to investigate the vibration response of the structure when crossed by the actual RDP train and simulate the response under future rail traffic scenarios (longer and/or heavier trains).

\section{Acknowledgments}

The Authors gratefully thank the Management of Transnet Freight Rail for supporting and financing the research on the Olifants River Viaduct, and the Concrete Materials and Structural Integrity Research Unit (CoMSIRU) of the University of Cape Town for the assistance in carrying out the dynamic tests.

\section{References}

1. International Heavy Haul Association (IHHA), http://www.ihha.net (2015)
2. P.C. Lombard, Sishen-Saldanha: First Six Years. Proc. $2^{\text {nd }}$ Int Heavy Haul Railway Conf. Colorado, USA: 13-21 (1982)

3. R.E. Von Gericke, Measures taken by the South African Transport Services to Reduce Transportation Costs of Coal on the Ermelo - Richards Bay Line. Proc. $3^{\text {rd }}$ Int Heavy Haul Railway Conf. Vancouver, Canada: 396-412 (1986)

4. W. Kuys, Ore Line Capacity Expansion: Conceptual Design of the Railway line to Increase Capacity. Proc. $9^{\text {th }}$ IHHA Conf. Shanghai, China: 941-949 (2009)

5. Transnet Integrated Report, http://www.transnet.net (2014)

6. P. Moyo, Condition Assessment of the Kalbaskraal and Olifants River Bridges. Technical Report. UCT, South Africa (2007)

7. J.D. Ngwenyama, P.N. Naiodoo, J.M. Mulder, 5 Years of Operational Experience and Lessons Learnt with the 342 wagon, 42000 ton, $3.85 \mathrm{~km}$, RadioDistributed Power Train on South Africa's Iron Ore Line. Proc. $10^{\text {th }}$ IHHA Conf. New Delhi, India: 796802 (2013)

8. F. Busatta, P. Moyo, Structural Health Monitoring of the Olifants River Viaduct. Proc. $11^{\text {th }}$ IHHA Conf. Perth, Australia: 850-860 (2015)

9. J. Bendat, A. Piersol, Engineering Applications of Correlation and Spectral Analysis, $2^{\text {nd }}$ Edition, John Wiley \& Sons Ltd (1993)

10. R. Brincker, L. Zhang, P. Andersen, Modal identification of output-only systems using frequency domain decomposition, Smart Mat Struct, 10, 3: 441445 (2001)

11. B. Peeters, G. De Roeck, Stochastic system identification for operational modal analysis: A review. ASME J Dyn Syst, Measur, and Contr, 123, 4: 659-667 (2001)

12. SVS, ARTeMIS Modal Pro v4.0, Structural Vibration Solutions A/S, Aalborg East, DK (2015)

13. F. Busatta, Dynamic Monitoring and Automated Modal Analysis of Large Structures: Methodological Aspects and Application to a Historic Iron Bridge. PhD Thesis, Politecnico di Milano (2012)

14. LabVIEW 2010, National Instruments, Austin TX (2010)

15. KAIROS Virtual Instruments, http://www.kairoscs.co.za (2015)

16. F. Busatta, P. Moyo, Design of a Monitoring System for the Olifants River Viaduct. Proc. $1^{\text {st }}$ South African Heavy Haul Association Conference. Johannesburg, South Africa. CD-ROM. 